\title{
Effect of Tunnel Structure of $\beta$-TCP on Periodontal Repair in Class III Furcation Defects in Dogs
}

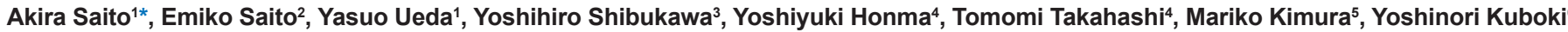 \\ and Hiroshi kato ${ }^{7}$ \\ ${ }^{1}$ Department of Oral Rehabilitation, Division of Oral Functional Science, Hokkaido University Graduate School of Dental Medicine, Sapporo, Japan \\ ${ }^{2}$ Departments of Periodontology and Endodontology, Division of Oral Health Science, Hokkaido University Graduate School of Dental Medicine, Sapporo, Japan. \\ ${ }^{3}$ Shibukawa Dental Clinics, Asahikawa, Japan. \\ ${ }^{4}$ Support Section for Education and Research, Division of Oral Health Science, Hokkaido University Graduate School of Dental Medicine, Sapporo, Japan. \\ ${ }^{5}$ PILOT corporation, Hiratsuka, Japan. \\ ${ }^{6}$ Hokkaido University Graduate School of Dental Medicine, Sapporo, Japan. \\ ${ }^{7}$ Kato Dental Clinic, Mito, Japan
}

\begin{abstract}
Background: The pore characteristics of bone graft materials play an important role in bone regeneration. Previous studies have reported that a pore size of $100 \sim 400 \mu \mathrm{m}$ effectively induces vascular invasion and cell population within the materials. Many graft materials used recently have macropore $(200 \sim 600 \mu \mathrm{m})$ or micropore $(0.1$ $\sim 1 \mu \mathrm{m})$ structures. We devised a bone material with a tunnel pipe structure and pore size of $300 \mu \mathrm{m}$. The present study evaluated periodontal healing following implantation of this new bone graft material in furcation class III defects.

Methods: Thirty mandibular premolar teeth of five beagles were used. After class III furcation defects were surgically created, each furcation was randomly treated with: 1) $\beta$-TCP with a tunnel pipe structure (tunnel group) $(n=10) ; 2)$ Granular $\beta$-TCP (granular group) $(n=10)$; and 3) No implant material (control group) $(n=10)$. The dogs were sacrificed 8 weeks post-surgery and healing was evaluated histologically.

Results: In the tunnel group, down growth of junctional epithelium was significantly less than that in the other two groups $(P<0.01)$ and bone formation and blood capillary invasion were observed in the inner part of pores of the implanted material in the furcation. However, little bone formation was observed between the granules in the granular group.
\end{abstract}

Conclusion: $\beta$ - TCP with a tunnel pipe structure and pore size of $300 \mu \mathrm{m}$ promotes bone regeneration and new cementum formation in class III furcation defects.

Keywords: Beta tricalcium phosphate; Tunnel structure; Bone grafting; Regeneration; Furcation; Animal model; Pore; Porosity

\section{Introduction}

Many studies have reported periodontal regeneration following implantation of autologous bone and artificial bone substitutes [1-4]. Bone grafting resulted in clinical improvements such as probing depth reduction and clinical attachment level gain in intrabony periodontal defects and class I and II furcation defects [2-4]. However, the treatment was associated with a relatively high degree of variability in clinical outcome [5]. Moreover, bone implantation in conjunction with guided tissue regeneration (GTR) membranes inhibited proliferation of epithelial tissues into furcation defects and increased periodontal regeneration [6-13]. This method, when combined with growth factors such as platelet-derived growth factor (PDGF), bone morphogenetic protein (BMP) and basic fibroblast growth factor (b FGF), accelerated bone formation and promoted periodontal regeneration [14-19]. However, it is still difficult to clinically achieve sufficient regeneration in class III furcation defects [20,21]. The geometric structure of implant materials was an important factor affecting the decision to induce either endochondral ossification or direct bone formation following subcutaneous BMP implantation into the back skin of rats [22-26]. A porous structure increased bone formation in the bone defect. Above all, the optimal pore size for differentiation and growth of osteoblasts and vascularization is approximately the same in both orthotopic and ectopic sites [22,24,27,28]. Recently, pore characteristics of implant materials, such as a tunnel structure and maintained pore size, have received much attention. A honeycomb structure in which many tunnels were arranged in the same direction accelerated vascular formation $[29,30]$. The tunnel structure also differentiated bone-marrow-derived stem cells into osteoblasts and promoted cell proliferation in vitro
$[27,30]$. We speculated that grafting materials with this tunnel structure could enhance the amount of bone formation in class III furcation defects. However, no investigations have been conducted.

In the present study, we employed $\beta$-TCP with a tunnel pipe structure in which the pipes were combined and irregularly arranged. The purpose of this study was to evaluate the effect of the tunnel pipe structure on periodontal regeneration following implantation of $\beta$-TCP in surgically created class III furcation defects in dogs.

\section{Materials and Methods}

\section{Tunnel-pipe-structure $\beta$-TCP}

The $\beta$-TCP slurry was obtained by kneading at molar ratio of 8:2:10 with tricalcium phosphate (Ca3(PO4)2) and polyvinyl alcohol and distilled water. Many cylindrical constructions having throughhole with an inner diameter of $300 \mu \mathrm{m}$, outer diameter of $500 \mu \mathrm{m}$ and length of 1-2 mm were made by extrusion molding of the slurry. The

*Corresponding author: Akira Saito, DDS, PhD, Department of Oral Rehabilitation Division of Oral Functional Science, Hokkaido University Graduate School of Denta Medicine Kita-13, Nishi-7, Kita-ku, Sapporo 060-8586, Japan, Tel: +81 117064275 Fax: +81 117064276 ; E-mail: saito@den.hokudai.ac.jp

Received Decenber 02, 2013; Accepted January 16, 2014; Published January 23, 2014

Citation: Saito A, Saito E, Ueda Y, Shibukawa Y, Honma Y, et al. (2014) Effect of Tunnel Structure of $\beta$-TCP on Periodontal Repair in Class III Furcation Defects in Dogs. Bioceram Dev Appl 4: 073. doi: 10.4172/2090-5025.1000073

Copyright: (c) 2014 Saito A, et al. This is an open-access article distributed unde the terms of the Creative Commons Attribution License, which permits unrestricted use, distribution, and reproduction in any medium, provided the original author and source are credited. 
constructions were collected and pressed with water releasing into the cube $(5 \times 5 \times 5 \mathrm{~mm})$ (Figures $1 \mathrm{~A}, 1 \mathrm{~B})$. Final $\beta$-TCP which tunnel pipe structure gathered and fixed were produced by sintering the structures at the maximum temperature of $1100^{\circ} \mathrm{C}$ in the presence of oxygen. The porosity of this tunnel-pipe $\beta$-TCP was $72 \%$, which included open porosity and closed porosity calculated as follows: porosity (\%) $=\left(1\right.$-bulk density of the sample/true density) $\times 100,{ }^{*}$ bulk density of the sample $=\mathrm{W} / \mathrm{V}$, ${ }^{*}$ true density $=3.07 / \mathrm{cm}^{3}(\beta-\mathrm{TCP})$. Data on the images obtained by X-ray powder diffraction (XRD) of tunnel-pipe $\beta$-TCP (Figure $1 \mathrm{C}$ ) were provided by the manufacturer. All diffractions peaks were assigned to single-phase $\beta$-TCP and no other phases were observed and the average crystal size was $175 \mathrm{~nm}$.

\section{Animals}

The experimental protocol (No. 08-0257) followed the guidelines for the care and use of laboratory animals of the Graduate School of Medicine, Hokkaido University. Five beagle dogs (female, 1 year old; mean weight $10.3 \mathrm{~kg}$ ) were used. All surgical procedures were performed under general anesthesia by an intramuscular injection of Medetomidine Hydrochloride ( $5 \mu \mathrm{g} / \mathrm{kg}$, Domitor ${ }^{\circledR}$; Meiji Seika, Tokyo, Japan) and Ketamine Hydrochloride $\left(2.9 \mathrm{mg} / \mathrm{kg}\right.$, Ketaral 50 ${ }^{\circ}$; Sankyo, Tokyo, Japan) and local infiltration (Xylocaine 2\% with 1:80,000 Epinephrine, Xylocaine ${ }^{\oplus}$; DENTSPLY SANKIN, Tokyo, Japan). The dogs were subjected to plaque control measures consisting of twiceweekly brushing and application of $0.5 \%$ Chlorhexidine Gluconate solution in order to establish healthy gingival conditions prior to surgical procedures (Figure 1D).

\section{Surgery and implantation}

Thirty mandibular premolar teeth were used. After reflection of a mucoperiosteal flap, the interradicular bone of all second, third and fourth premolars was completely removed with rotating burs under irrigation and hand micro ochsenbein chisels to create throughand-through furcation defects. The defect height from the cementoenamel junction (CEJ) to the reduced alveolar crest was $4 \mathrm{~mm}$. The exposed root surfaces were planted with curettes in order to remove the periodontal ligament and cementum (Figure 1E). At this point, the teeth were randomly assigned to one of three treatment groups based on a random computer-generated list. In the tunnel group $(n=10), \beta$-TCP was shaped using a diamond bur and knife to fit the furcation space. Then, $\beta$-TCP was implanted into the furcation and the remaining space was filled with the pipe particles of $\beta$-TCP (Figure. 1F). In the granular group $(n=10)$, the furcation defect was filled with granular $\beta$-TCP which was prepared by crushing the pipe tunnel structure of $\beta$-TCP mechanically. The furcation was not treated in the remaining ten teeth, which served as control. After implantation, the flaps were positioned with the gingival margins of the flaps at the CEJ and sutured.

\section{Wound management}

Sutures were removed 10 days after the surgical procedure (Figure 1G). Plaque control measures included weekly brushing and application of $0.5 \%$ Chlorohexadine Gluconate solution throughout the healing period.

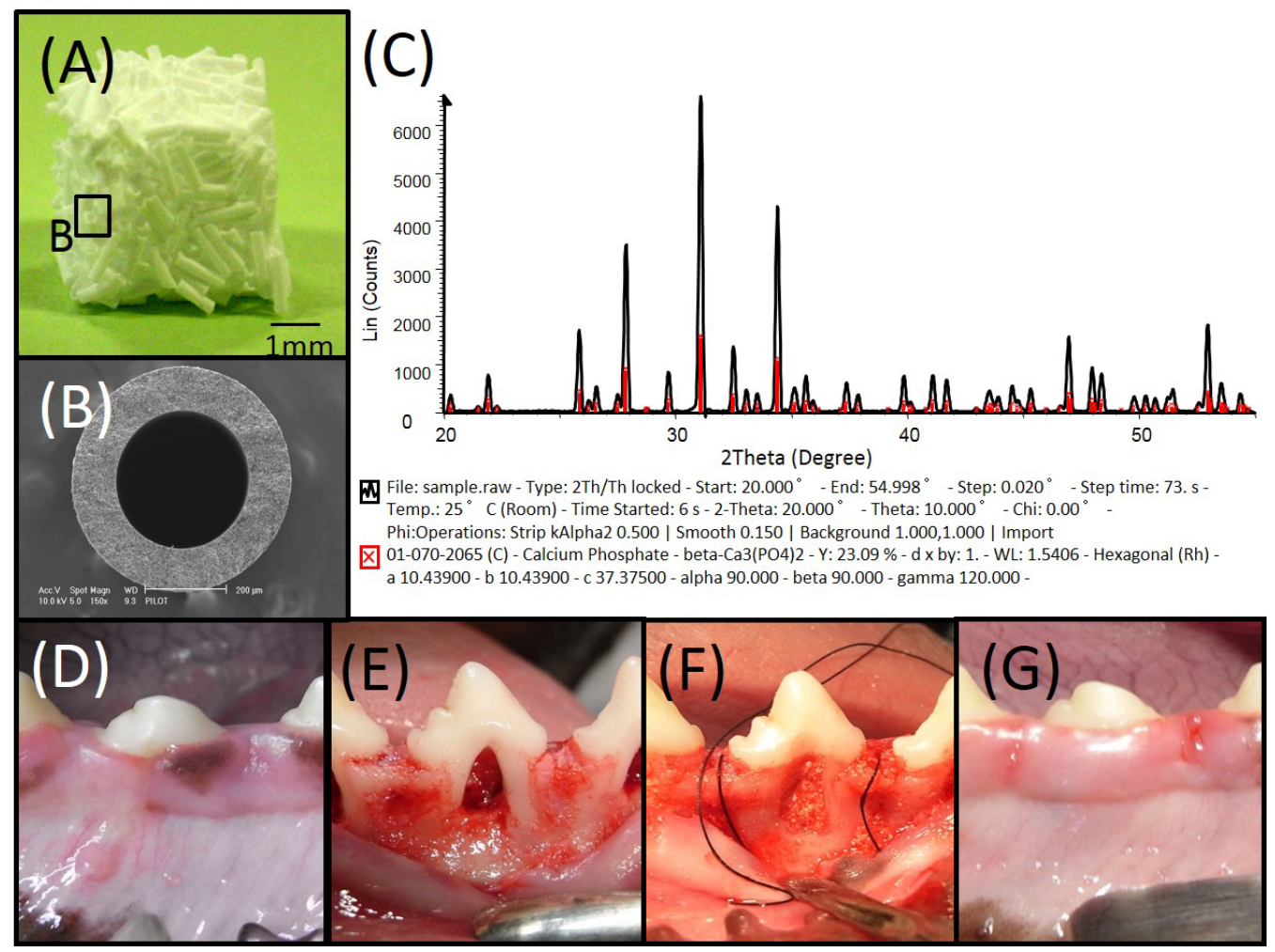

Figure 1: Structure of tunnel-pipe $\beta$-TCP and surgical procedure.

A) A cube with sides of $5 \mathrm{~mm}$ was formed by gathering and connecting irregularly arranged pieces of tunnel-pipe $\beta$-TCP. B) The tunnel; inner diameter of $300 \mu \mathrm{m}$, outer diameter of $500 \mu \mathrm{m}$ and length of $1-2 \mathrm{~mm} \mathrm{C}$ ) The tunnel-pipe $\beta$-TCP was composed of highly crystalline and single-phase $\beta$-TCP, and no other phases were observed. D) Pre-operative image. E) Class III furcation defect preparation F) Placement of $\beta$-TCP. G) Post-operative healing at 8 weeks. Minimal post-operative inflammation and slight gingival recession were noted. 
Citation: Saito A, Saito E, Ueda Y, Shibukawa Y, Honma Y, et al. (2014) Effect of Tunnel Structure of $\beta$-TCP on Periodontal Repair in Class III Furcation Defects in Dogs. Bioceram Dev Appl 4: 073. doi: 10.4172/2090-5025.1000073

\section{Histological processing and histometric analysis}

The dogs were sacrificed 8 weeks after the surgical procedure. Tissue blocks including teeth, bone and soft tissues were resected. Blocks were fixed in 10\% buffered formalin, decalcified in 10\% Ethylene Diamine Tetra Acetic Acid (EDTA, Wako, Tokyo, Japan) solution, trimmed, dehydrated, and embedded in paraffin. Serial sections of thickness $4 \mu \mathrm{m}$ were prepared in the mesio-distal plane. Sections were then prepared from the area in the middle of the buccal section containing the line connecting the buccal surfaces of the mesial and distal roots and the lingual section containing the line connecting the lingual surfaces of the mesial and distal roots. Three bucco-lingual sections ( $52 \mu \mathrm{m}$ apart) were stained with hematoxylin and eosin and the nearby sections were stained with Tartrate-Resistant Acid Phosphatase (TRAP) stain. Measurements of each specimen were carefully performed by a single examiner (YH) (Figure 2). Pre study calibration exercises revealed that the intra examiner calibration error was $<5 \%$ for all parameters measured. Three sections stained with hematoxylin and eosins were evaluated. The area from the apical border of the mesial and distal roots to the fornix was measured with an image analysis system (Image Pro Plus ver.6.2; Media Cybernetics, Inc. Tokyo, Japan). For determination of the defect size, the defect width was recorded by measuring the distance between the mesial and distal endpoints of root planning and the defect height was recorded by measuring the distance between the top of furcation and the center of a line connecting the end points of root planning on the mesial and distal root surfaces (Figure 2A). The

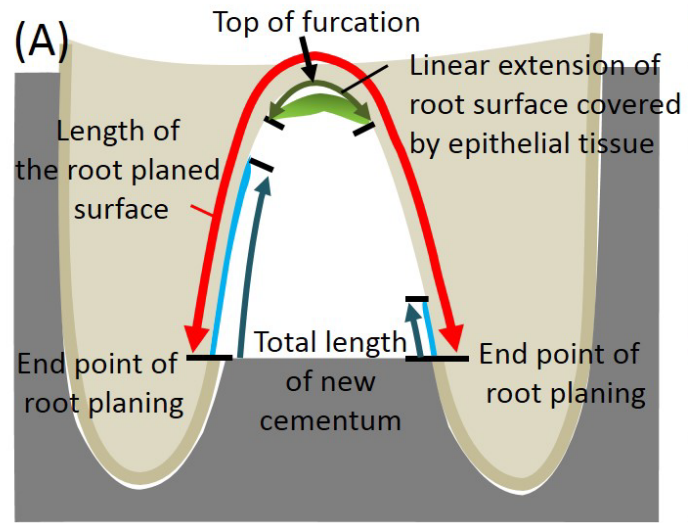

(B)

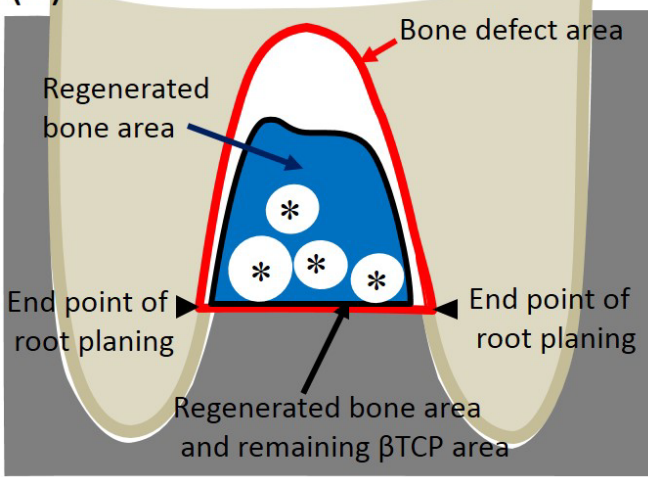

Figure 2: Schematic illustration of landmarks used for histometric measurements.

A) Schematic illustration of the regenerated bone and/or $\beta$-TCP. B) Schematic illustration of the regenerated new cementum and epithelial tissue. AR=apical end of the root planed surface; Black asterisk=remaining $\beta$-TCP.

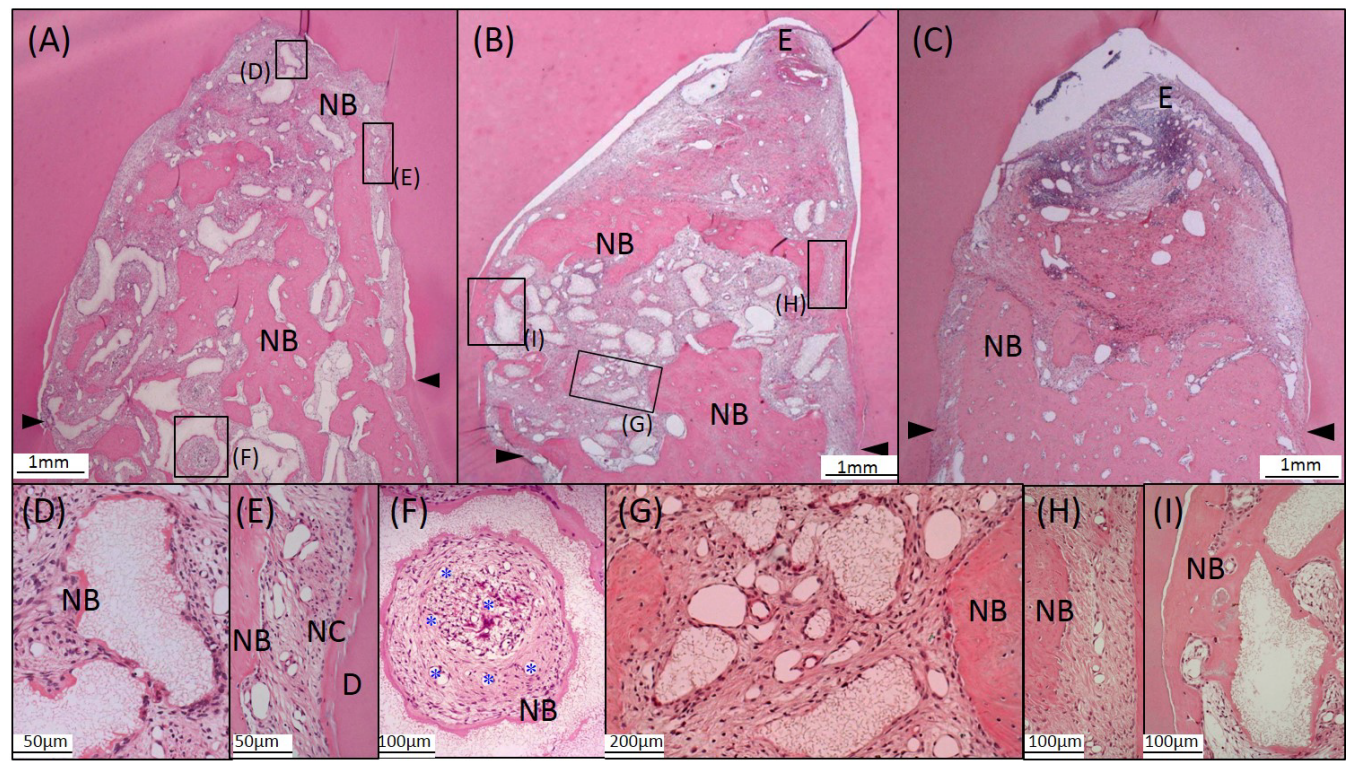

Figure 3: Representative cases from three groups after the 8-week healing period (hematoxylin and eosin stain).

$(A),(D),(E)$ and $(F)$ the tunnel group. (A) Overview: Note the extensive new bone (NB) formation and small amounts of $\beta$-TCP. (D) NB had formed on the outer surfaces of $\beta$-TCP. (E) New connective tissue fibers were oriented parallel or inclined to the root surface and embedded in both new cementum (NC) and NB. (F) NB had formed on the outer surfaces and the inner surfaces of $\beta$-TCP. Blood vessels (Blue asterisks) had formed in the center of the pipe tunnel. (B), (G), $(\mathrm{H})$ and $(\mathrm{I})$ the granular group. (B)Overview: Gingival epithelium $(\mathrm{E})$ was observed in the fornix of the furcation. NB was observed near the residual bone and surrounding $\beta$-TCP. (G) Fibroblasts and small amount of new bone were observed surrounding $\beta$-TCP particles. (H) New connective tissue fibers oriented parallel or inclined to the root surface and embedded in both new cementum and NB. (I) New cementum with localized areas of ankylosis originating from the same bone that had formed around the $\beta$-TCP. (C) The control group. E was observed in the fornix of the furcation. Limited NB had formed at the bottom of the furcation defect near the residual bone. Filled arrowhead=the apical end of root-planed surface; $D=$ root dentin. 
area from the apical border of the mesial and distal roots to the fornix was regarded as bone defect area (BDA) (Figure 2B). The tissues formed from the apical border in a coronal direction after each treatment was regarded as the newly formed tissue.

The following parameters were also determined:

1) The percentage of regenerated bone area $(\mathrm{NBR})$ : regenerated bone area / BDA $\times 100$;

2) The percentage of space composed of new bone and $\beta$-TCP (BTR): regenerated bone area and remaining $\beta$-TCP area / $\mathrm{BDA} \times 100$;

3) The percentage of epithelium (ER): linear extension of root surface covered by epithelial tissue / length of the root surface from the mesial notch to the distal notch $\times 100$;

4) The percentage of regenerated cementum length (NCR): total length of regenerated cementum / length of the root surface from the mesial notch to the distal notch $\times 100$.

\section{Data analysis}

The mean \pm SD of each measurement was calculated for each tooth from selected sections. Statistical differences were analyzed using the Kruskal-Wallis test.

\section{Results}

\section{Clinical observations}

Clinical healing after the surgical procedures was uneventful with minimum indications of inflammation throughout the experimental period.

\section{Histological observations}

In the tunnel group, down growth of gingival epithelium was not observed in the furcation of $8 / 10$ specimens (Figure $3 \mathrm{~A}$ ). Small amounts of $\beta$-TCP remained within the defects. New bone had formed on the resorbed inner and outer surfaces of $\beta$-TCP and between the implant materials and the root-planed surface (Figures 3D through $3 \mathrm{~F}$ ). Blood vessels had formed in the center of each pipe tunnel directed horizontally (Figure 3F). Numerous multinucleated cells adhered to the $\beta$-TCP surface and there was new bone in the whole of the furcation (Figures $4 \mathrm{~A}$ through $4 \mathrm{D}$ ). New cementum had formed on the root-planed surface near the top of the furcation space. New connective tissue fibers oriented parallel or inclined to the root surface and embedded in both new cementum and new bone were observed (Figure 3E). Ankylosis was observed in the furcation of $1 / 10$ specimens. However, there was no evidence of active root resorption. In the granular group, gingival epithelium was observed in the fornix of the furcation in all specimens (Figure 3B). New bone had formed in two-thirds of the furcation defect. The new bone was observed near the residual bone and surrounding $\beta$-TCP. In the middle portion of the defects, fibroblasts and blood vessels were observed in the space between $\beta$-TCP particles (Figure $3 \mathrm{G})$. The multinucleated cells adhered to the $\beta$-TCP surface and new bone (Figures $4 \mathrm{E}$ through $4 \mathrm{H}$ ). New cementum with inserting collagen fibers had formed on the root-planed surface. New connective tissue fibers oriented parallel or inclined to the root surface were observed (Figure 3H). Ankylosis (Figure 3I) was observed in the furcation of $2 / 10$ specimens. However, there was no evidence of active root resorption. In the control group, gingival epithelium was observed in the fornix of the furcation in all specimens and inflammatory cells appeared to be in the connective tissue under the epithelium (Figure 3C). Limited new bone had formed at the bottom of the furcation defect near the residual bone. Limited amounts of new cementum with inserting collagen fibers had formed on the bottom half of the root-planed surface (Figure 3C). None of the specimens showed areas of ankylosis.

\section{Histometric analysis}

There were no significant differences in bone defect area or root length among the three groups. The gingival epithelium was significantly less in the tunnel group compared to the control group and granular group $(\mathrm{P}<0.01)$ (Table 1$)$. New bone area and space composed of new bone and $\beta$-TCP were significantly greater in the tunnel group compared to the control group and granular group $(\mathrm{P}<0.01$; Table 1$)$. Newly formed cementum was $75.2 \pm 8.1 \%$ in the

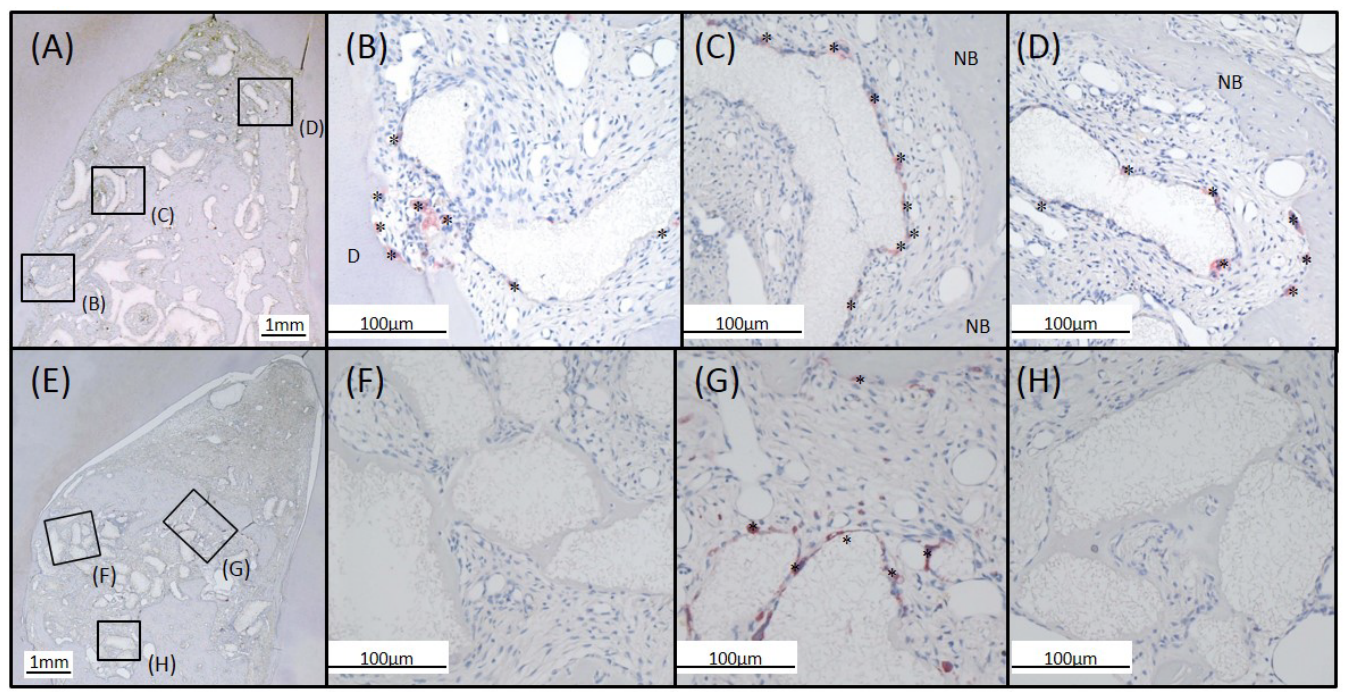

Figure 4: Photographs from the tunnel and the granular groups with TRAP stain.

(A) Through (D) the tunnel group. (A) Overview; Numerous multinucleated cells in the whole of the furcation. (B) Through (D) multinucleated cells (black asterisks) adhered to the $\beta$-TCP surface and there was new bone in the whole of the furcation. (E) through (H) the granular group. (E) Overview: Multinucleated cells adhered to new bone in some locations. $(F)$ and $(H)$ Multinucleated cells were not observed on new bone. (G) Multinucleated cells (black asterisks) adhered to the $\beta$-TCP surface or NB. NB=new bone. 
(Group mean \pm SD in percentage)

\begin{tabular}{|c|c|c|c|}
\hline Parameter & Control Group & Granular group & Tunnel group \\
\hline New bone area (NBR) & $25.9 \pm 4.1^{\mathrm{t}}$ & $29.8 \pm 4.5^{\S}$ & $42.0 \pm 5.9^{1} \S$ \\
\hline Space composed of new bone and $\beta$ TCP(SBTR) & $25.9 \pm 4.1^{\sharp}$ & $50.8 \pm 6.5^{\ddagger}$ & $74.6 \pm 4.2^{* \pm}$ \\
\hline Epithelial tissue (ER) & $48.1 \pm 3.9^{1}$ & $21.4 \pm 4.4^{*}$ & $6.5 \pm 8.1^{* \mathrm{I}}$ \\
\hline New cementum (NCR) & $28.3 \pm 5.1^{\text {F }}$ & $51.9 \pm 12.0^{* \neq}$ & $75.2 \pm 8.1^{\star_{1}}$ \\
\hline Root resorption (RRR) & $0.0 \pm 0.0$ & $1.9 \pm 5.2$ & $0.0 \pm 0.0$ \\
\hline Ankylosis (AKR) & $0.0 \pm 0.0^{\ddagger}$ & $7.7 \pm 6.7^{\star \neq}$ & $0.7 \pm 1.7^{*}$ \\
\hline \multicolumn{4}{|l|}{ (Group mean \pm SD in mm) } \\
\hline Parameter & Control Group & Granular group & Tunnel group \\
\hline Width of furcation & $2.5 \pm 0.3$ & $2.4 \pm 0.3$ & $2.5 \pm 0.3$ \\
\hline Height of furcation & $3.5 \pm 0.3$ & $3.5 \pm 0.1$ & $3.5 \pm 0.2$ \\
\hline
\end{tabular}

*Tunnel group vs Granular group ( $p<0.01)$; Kruskal-Wallis test; statistical differences between the three groups.

'Tunnel group vs Control group ( $p<0.01$ ); Kruskal-Wallis test; statistical differences between the three groups.

Granular group vs Control group $(p<0.05)$; Kruskal-Wallis test; statistical differences between the three groups.

$\S$ Tunnel group vs Granular group $(p<0.05)$; Kruskal-Wallis test; statistical differences between the three groups.

$\mathrm{SD}=$ standard deviation

Table 1: Histometric Analysis of Periodontal Healing.

tunnel group, significantly greater than that in the granular group and control group $(\mathrm{P}<0.01$; Table 1$)$.

\section{Discussion}

B-TCP is well known as a biodegradable material with good osteo conductive capacity and has been used in periodontology as a bone graft substitute $[1,6]$.The present study has demonstrated that the distinct influence of granular structure and tunnel pipe structure $\beta$-TCP on periodontal regeneration. The $\beta$-TCP employed in previous studies had a granular structure with both micro-porosity and nanoporosity $[1,6]$. Wada et al. [1] reported that new bone formed in about half of the defect when $\beta$-TCP was implanted in surgically created class III furcation defects of animal models [6]. The amount of new bone formation was similar to that in the granular group in the present study (50.8\%). On the other hand, the tunnel pipe structure promoted new bone formation in class III furcation defects in the present study. Rodriguez et al. [30] reported that the honeycomb structure containing parallel tunnels increased vessel invasion and formation and enhanced cellular proliferation of bone-marrow stromal cells [30]. It also induced differentiation and proliferation of bone marrow-derived mesenchymal stem cells into osteoblasts in vitro [27]. In the present study, the tunnel structure might have served as an efficient conductor for vessel invasion. It enables easy vascular invasion in the whole carrier, thus supplying oxygen to the cells during the initial healing stage and bone formation was induced in a linear direction to the residual bone. New bone had formed inside the tunnel structure not only near the residual bone but also towards the top of the defect. The resorptive mechanism of $\beta$-TCP in vivo involves chemical dissolution $[31,32]$ and phagocytosis by osteoclasts $[19,33]$. Some previous studies using $\beta$-TCP have reported the appearance of osteoclasts. Many osteoclasts were observed in the furcation defect of the tunnel group when compared with the granular group. This result was in agreement with the findings of a previous report which suggested that the number of osteoclasts on the surface of $\beta$-TCP would depend on the $3 \mathrm{D}$ conformation of the space structures [14]. Increase in the number of osteoclasts induced by the tunnel structure might promote the resorption of residual $\beta$-TCP in the future. The osteoblasts beside the osteoclasts actively formed osteoid not only on the surface of $\beta$-TCP but also on the bone surface in contact with $\beta$-TCP. The new bone mostly consisting of woven bone still showed high bone turnover throughout the 8 weeks after the surgery. Further research is needed to clarify how the periodontal regeneration was affected by the high bone turnover.

In the tunnel group, new cementum formed on the root surface from the apical extent of root planning towards the coronal portion in the furcation defect. New cementum consisted of hard tissue deposited on the resorption lacunae. These findings would be associated with enhanced bone formation and high bone turnover. The odontoclasts had similar expression patterns of cathepsin K and Matrix MetalloProteinase-9 (MMP-9) as osteoclasts [34]. The odontoclasts could have been stimulated by the active bone formation and high bone turnover. Preparation for new cementum formation might start adjacent to the resorption areas when root resorption was most active [35]. Consequently, the tunnel structure of $\beta$-TCP would induce new cementum formation.

In this study, ankylosis was observed in a few specimens in both the granular and tunnel groups. New bone connected to new cementum on the root surface; however, there was no evidence of active root resorption. Similar ankylosis was also observed in previous studies [3639]. When biomaterials with osteoconductive property were implanted near the root surface, new bone that formed around the biomaterials connected to new cementum on the root surface. However, there were few areas of ankylosis and periodontal ligament space was established during wound healing [38-42]. Occlusal loading may play an important role in the repair process by replacing areas of ankylosis with a periodontal ligament space [38-40, 43]. However, this could not be clarified in the present study due to methodological limitations. A well-designed experiment of longer duration is required to accurately determine the changes in ankylotic union. Within the limitations of the present animal study, it can be concluded that the tunnel structure of $\beta$-TCP induced an increase in cells and blood vessels derived from the residual bone, which enhanced periodontal regeneration. However, ankylosis was observed in a few specimens. It is not clear whether ankylosis is a transient phenomenon. Further short- and long-term studies are required to clarify the difference in clinical outcomes of regenerative therapy in a larger number of furcation defects under strictly standardized conditions.

\section{Conclusion}

This study demonstrated that the tunnel structure induced an increase in cells and blood vessels derived from the residual bone, 
which enhanced periodontal regeneration in class III furcation defects. However, ankylosis was observed in a few specimens.

\section{Conflict of interest and Source of Funding Statement}

The authors declare that they have no conflict of interests. This study was supported by Grants-in-Aid for Encouragement of Young Scientists (22792078) and Scientific Research (22592307) from the Ministry of Education, Science, Sports and Culture of Japan.

\section{Significance of Research}

Scientific rationale for the study: This study was performed with the aim to improve the biological performance of $\beta$-tricalcium phosphate ( $\beta$-TCP) for periodontal repair.

\section{Principal Findings}

Tunnel structure of materials can improve the performance of $\beta$-TCP implantation when compared with granular structure.

\section{Practical Implications}

Tunnel structure may be promising candidates for $\beta$-TCP implantation. Moreover the important pore structure may be taken care not to crash when mixing with clot or filling into defects.

\section{Acknowledgement}

The authors declare that they have no conflict of interests. This study was supported by Grants-in-Aid for Encouragement of Young Scientists (22792078) and Scientific Research (22592307) from the Ministry of Education, Science, Sports and Culture of Japan.

\section{References}

1. Wada T, Wu CH, Sugita H, Sugita N, Katagiri S, et al. (1989) Autogenous, allogenic, and beta-TCP grafts: comparative effectiveness in experimental bone furcation defects in dogs. J Oral Implantol 15: 231-236.

2. Stavropoulos A, Windisch P, Szendröi-Kiss D, Peter R, Gera I, et al. (2010) Clinical and histologic evaluation of granular Beta-tricalcium phosphate for the treatment of human intrabony periodontal defects: a report on five cases. $J$ Periodontol 81: 325-334.

3. Stein JM, Fickl S, Yekta SS, Hoischen U, Ocklenburg C, et al. (2009) Clinica evaluation of a biphasic calcium composite grafting material in the treatment of human periodontal intrabony defects: a 12-month randomized controlled clinical trial. J Periodontol 80: 1774-1782.

4. Tsao YP, Neiva R, Al-Shammari K, Oh TJ, Wang HL (2006) Effects of a mineralized human cancellous bone allograft in regeneration of mandibular Class II furcation defects. J Periodontol 77: 416-425.

5. Sculean A, Nikolidakis D, Schwarz F (2008) Regeneration of periodontal tissues: combinations of barrier membranes and grafting materials - biological foundation and preclinical evidence: a systematic review. J Clin Periodontol 35: 106-116.

6. Belal MH, Al-Noamany FA, El-Tonsy MM, El-Guindy HM, Ishikawa I (2005) Treatment of human class II furcation defects using connective tissue grafts bioabsorbable membrane, and resorbable hydroxylapatite: a comparative study. J Int Acad Periodontol 7: 114-128.

7. Döri F, Huszár T, Nikolidakis D, Tihanyi D, Horváth A, et al. (2008) Effect of platelet-rich plasma on the healing of intrabony defects treated with Beta tricalcium phosphate and expanded polytetrafluoroethylene membranes. J Periodontol 79: 660-669.

8. Zafiropoulos GG, Hoffmann O, Kasaj A, Willershausen B, Weiss O, et al. (2007) Treatment of intrabony defects using guided tissue regeneration and autogenous spongiosa alone or combined with hydroxyapatite/beta-tricalcium phosphate bone substitute or bovine-derived xenograft. J Periodontol 78: 22162225.

9. Christgau M, Moder D, Wagner J, Glässl M, Hiller KA, et al. (2006) Influence of autologous platelet concentrate on healing in intra-bony defects following guided tissue regeneration therapy: a randomized prospective clinical splitmouth study. J Clin Periodontol 33: 908-921.

10. Lekovic V, Camargo PM, Weinlaender M, Vasilic N, Aleksic Z, et al. (2003) Effectiveness of a combination of platelet-rich plasma, bovine porous bone mineral and guided tissue regeneration in the treatment of mandibular grade II molar furcations in humans. J Clin Periodontol 30: 746-751.

11. Simonpietri-C JJ, Novaes AB Jr, Batista EL Jr, Filho EJ (2000) Guided tissue regeneration associated with bovine-derived anorganic bone in mandibular class II furcation defects. 6-month results at re-entry. J Periodontol 71: 904-911.

12. Kothiwale SV, Anuroopa P, Gajiwala AL (2009) A clinical and radiological evaluation of DFDBA with amniotic membrane versus bovine derived xenograft with amniotic membrane in human periodontal grade II furcation defects. Cell Tissue Bank 10: 317-326.

13. De Leonardis D, Garg AK, Pedrazzoli V, Pecora GE (1999) Clinical evaluation of the treatment of class II furcation involvements with bioabsorbable barriers alone or associated with demineralized freeze-dried bone allografts. J Periodontol 70: 8-12.

14. Irokawa D, Ota M, Yamamoto S, Shibukawa Y, Yamada S (2010) Effect of Î tricalcium phosphate particle size on recombinant human platelet-derived growth factor-BB-induced regeneration of periodontal tissue in dog. Dent Mater J 29: 721-730

15. Ridgway HK, Mellonig JT, Cochran DL (2008) Human histologic and clinica evaluation of recombinant human platelet-derived growth factor and betatricalcium phosphate for the treatment of periodontal intraosseous defects. Int J Periodontics Restorative Dent 28: 171-179.

16. Lee JS, Wikesjo UM, Jung UW, Choi SH, Pippig S, et al. (2010) Periodonta wound healing/regeneration following implantation of recombinant human growth/differentiation factor- 5 in a beta-tricalcium phosphate carrier into onewall intrabony defects in dogs. J Clin Periodontol 37:382-389.

17. Anzai J, Kitamura M, Nozaki T, Nagayasu T, Terashima A, et al. (2010) Effects of concomitant use of fibroblast growth factor (FGF)-2 with beta-tricalcium phosphate $\left(\hat{I}^{2}\right.$-TCP) on the beagle dog 1-wall periodontal defect model. Biochem Biophys Res Commun 403: 345-350.

18. Shirakata Y, Taniyama K, Yoshimoto T, Miyamoto M, Takeuchi N, et al. (2010) Regenerative effect of basic fibroblast growth factor on periodontal healing in two-wall intrabony defects in dogs. J Clin Periodontol 37: 374-381.

19. Oi Y, Ota M, Yamamoto S, Shibukawa Y, Yamada S (2009) Beta-tricalcium phosphate and basic fibroblast growth factor combination enhances periodontal regeneration in intrabony defects in dogs. Dent Mater J 28: 162-169.

20. Mellonig JT, Valderrama Mdel P, Cochran DL (2009) Histological and clinica evaluation of recombinant human platelet-derived growth factor combined with beta tricalcium phosphate for the treatment of human Class III furcation defects. Int J Periodontics Restorative Dent 29: 169-177.

21. Palioto DB, Joly JC, de Lima AF, Mota LF, Caffesse R (2003) Clinical and radiographic treatment evaluation of class III furcation defects using GTR with and without inorganic bone matrix. J Clin Periodontol 30: 1-8.

22. Kuboki Y, Jin Q, Takita H (2001) Geometry of carriers controlling phenotypic expression in BMP-induced osteogenesis and chondrogenesis. J Bone Joint Surg Am 83-83A Suppl 1: S105-15.

23. Jin QM, Takita H, Kohgo T, Atsumi K, Itoh H, et al. (2000) Effects of geometry of hydroxyapatite as a cell substratum in BMP-induced ectopic bone formation. J Biomed Mater Res 52: 491-499.

24. Tsuruga E, Takita H, Itoh H, Wakisaka Y, Kuboki Y (1997) Pore size of porous hydroxyapatite as the cell-substratum controls BMP-induced osteogenesis. J Biochem 121: 317-324

25. Kuboki Y, Saito T, Murata M, Takita H, Mizuno M, et al. (1995) Two distinctive BMP-carriers induce zonal chondrogenesis and membranous ossification, respectively; geometrical factors of matrices for cell-differentiation. Connect Tissue Res 32: 219-226.

26. Kuboki Y, Takita H, Kobayashi D, Tsuruga E, Inoue M, et al. (1998) BMP induced osteogenesis on the surface of hydroxyapatite with geometrically feasible and nonfeasible structures: topology of osteogenesis. J Biomed Mater Res 39: 190-199.

27. George J, Kuboki Y, Miyata T (2006) Differentiation of mesenchymal stem cells into osteoblasts on honeycomb collagen scaffolds. Biotechnol Bioeng 95: 404411.

28. Götz HE, Müller M, Emmel A, Holzwarth U, Erben RG, et al. (2004) Effect of surface finish on the osseointegration of laser-treated titanium alloy implants. Biomaterials 25: 4057-4064. 
Citation: Saito A, Saito E, Ueda Y, Shibukawa Y, Honma Y, et al. (2014) Effect of Tunnel Structure of $\beta$-TCP on Periodontal Repair in Class III Furcation Defects in Dogs. Bioceram Dev Appl 4: 073. doi: 10.4172/2090-5025.1000073

29. Kuboki Y, Iku S, Yoshimoto R, Kaku T, Takita H, et al. (2009) Calcified Honeycomb-shaped Collagen Maintains its Geometry in Vivo and Effectively Induces Vasculature and Osteogenesis. Nano Biomedicine 1:85-94.

30. Rodriguez AP, Missana L, Nagatsuka H, Gunduz M, Tsujigiwa H, et al. (2006) Efficacy of atelocollagen honeycomb scaffold in bone formation using KUSA/A1 cells. J Biomed Mater Res A 77: 707-717.

31. Daculsi G, LeGeros RZ, Nery E, Lynch K, Kerebel B (1989) Transformation of biphasic calcium phosphate ceramics in vivo: ultrastructural and physicochemical characterization. J Biomed Mater Res 23: 883-894.

32. Ellies LG, Nelson DG, Featherstone JD (1992) Crystallographic changes in calcium phosphates during plasma-spraying. Biomaterials 13: 313-316.

33. Zerbo IR, Bronckers AL, de Lange G, Burger EH (2005) Localisation of osteogenic and osteoclastic cells in porous beta-tricalcium phosphate particles used for human maxillary sinus floor elevation. Biomaterials 26: 1445-1451.

34. Tsuchiya M, Akiba Y, Takahashi I, Sasano Y, Kashiwazaki J, et al. (2008) Comparison of expression patterns of cathepsin K and MMP-9 in odontoclasts and osteoclasts in physiological root resorption in the rat molar. Arch Histo Cytol 71: 89-100.

35. Kimura R, Anan H, Matsumoto A, Noda D, Maeda K (2003) Dental root resorption and repair: histology and histometry during physiological drift of rat molars. J Periodontal Res 38: 525-532.

36. Nery EB, Eslami A, Van Swol RL (1990) Biphasic calcium phosphate ceramic combined with fibrillar collagen with and without citric acid conditioning in the treatment of periodontal osseous defects. J Periodontol 61: 166-172.

37. Kim CK, Cho KS, Choi SH, Prewett A, Wikesjö UM (1998) Periodontal repair in dogs: effect of allogenic freeze-dried demineralized bone matrix implants on alveolar bone and cementum regeneration. J Periodontol 69: 26-33.

38. King GN, Hughes FJ (1999) Effects of occlusal loading on ankylosis, bone and cementum formation during bone morphogenetic protein-2-stimulated periodontal regeneration in vivo. J Periodontol 70: 1125-1135.

39. Takahashi D, Odajima T, Morita M, Kawanami M, Kato H (2005) Formation and resolution of ankylosis under application of recombinant human bone morphogenetic protein-2 (rhBMP-2) to class III furcation defects in cats. J Periodontal Res 40: 299-305.

40. Wesselink PR, Beertsen W (1994) Ankylosis of the mouse molar after systemic administration of 1-hydroxyethylidene-1,1-bisphosphonate (HEBP). J Clin Periodontol 21: 465-471.

41. King GN, King N, Hughes FJ (1998) Effect of two delivery systems for recombinant human bone morphogenetic protein-2 on periodontal regeneration in vivo. J Periodontal Res 33: 226-236.

42. Blomlöf L, Lindskog S (1994) Quality of periodontal healing. II: Dynamics of reparative cementum formation. Swed Dent J 18: 131-138.

43. EIDeeb ME, Andreasen JO (1991) Histometric study of the effect of occlusa alteration on periodontal tissue healing after surgical injury. Endod Dent Traumatol 7: 158-163. 